\title{
EFFECT OF TUBE DIAMETER AND SURFACE ROUGHNESSON FLUID FLOW FRICTION FACTOR
}

\author{
Mirmanto*, I GNK Yudhyadi, Emmy Dyah S. \\ Mechanical Engineering Department, Mataram University, JI. Majapahit No. 62, \\ Mataram, NTB, 83125, Indonesia \\ *E-mail: mmirmanto@gmail.com
}

\begin{abstract}
Experiments have been performed to investigate the effect of channel roughness and diameter on fluid friction. Three different diameters and roughness of tubes were used to examine the friction factor. The first tube made of stainless steel with an inner diameter of 1.14 $\mathrm{mm}$ was investigated at Brunel University, whilst the others made of PVC with diameters of 17 $\mathrm{mm}$ and $15.5 \mathrm{~mm}$ rough were tested at Mataram University. The stainless steel was equipped with a $200 \mathrm{~mm}$ calming section and smooth one. The $15.5 \mathrm{~mm}$ diameter tube was coated internally with sand that had an average grain size of $0.5 \mathrm{~mm}$ so that the tube had a relative roughness of 0.032 . The last tube with a diameter of $17 \mathrm{~mm}$ was smooth as explained in the H408 Fluid Friction Experimental Apparatus manual.

The results indicate that the flow in the stainless steel tube still obeys the theory and in the $17 \mathrm{~mm}$ tube shows a deviation in friction factor with the theory. However, this was due to no calming section installed in the test rig. Flow in the rough tube $(15.5 \mathrm{~mm}$ diameter) demonstrates that the Reynolds number does not affect the friction factor in turbulent regimes and the experimental friction factors were reasonably in a good agreement with the theory or Moody diagram. Hence, the effect of decreasing in diameter of channels on friction factor is insignificant.
\end{abstract}

Keywords: friction factor, surface roughness, fluid friction theory.

\section{Background}

Friction factors are important parameters in a process that utilizes fluid flow. This can cause high pressure drops which further cause high demands of pumping energy. Processes that use small tubes/channels need carefully pressure drop calculations because in smaller tubes, the pressure drop becomes significantly higher than in bigger tubes. Even, in microchannels the pressure drop is one of the major problems that must be solved or eliminated correctly and still being a concerned problem in this field study. Researches on this field are still challenging the microchannel communities.

Still there are many contradictory conclusions on the definition of microchannels. Previous studies used flow behaviour as criteria to define microchannels, e.g. Brauner and Moalem-Maron [1], Kewand Cornwell [2], and Peng and Wang [3]. On the other hand, some studies used a dimension of channels to differ microchannel from macrochannel. Mehendale et al. [4] classified heat exchangers in general, in terms of $D_{h}$ :

(a) Micro heat exchanger: $D_{h}=1-100 \mu \mathrm{m}$. (b) Meso heat exchanger: $D_{h}=100 \mu \mathrm{m}-1$ $\mathrm{mm}$.

(c) Compact/macro heat exchanger: $D_{h}=1$ $-6 \mathrm{~mm}$.

(d) Conventional heat exchanger: $D_{h}>6 \mathrm{~m}$. Finally, based on engineering practice and application areas, such as refrigeration industry in small tonnage units, compact evaporators, cryogenic industries, cooling elements of microelectronics and microelectromechanical systems (MEMS), Kandlikar [5] subdivided channels into three groups in terms of $D_{h}$, as follows:

(a) Conventional channels: $D_{h}>3 \mathrm{~mm}$.

(b) Minichannels: $D_{h}=200 \mu \mathrm{m}-3 \mathrm{~mm}$.

(c) Microchannels: $D_{h}=10-200 \mu \mathrm{m}$.

Research results published in the open literatures are seem different each other. Some previous studies stated that friction factors in large diameter tubes differed from those in small/micro tubes. Some indicated higher friction factors, e.g. Urbanek et al. [6], Papautsky et al. [7], Pfund et al. [8], Shen et al. [9]. Other studies showed no distinction between experimental friction factors and theory, e.g. Silverio and Moreira [11], Akbari et al. [12], Mirmanto et al. [13]. However, several studies presented friction factors that 
are lower than the theory, e.g. Jiang et al. [14].

The reasons of being higher than the theory are usually due to entrance effect, roughness effect, dimension errors and flow measurements. Qu et al. [15] demonstrated relatively high friction factors from conventional theory when they measured pressure drops for water flowing in trapezoidal silicon microchannels with hydraulic diameters ranging from $51 \mu \mathrm{m}$ to $169 \mu \mathrm{m}$. Their friction factors were about $8 \%$ to $38 \%$ higher than theory. However, they justified the deviation as being the result of the high relative roughness (3.5\% to $5.7 \%$ ). Jiang et al. [16], who used a microchannel with a hydraulic diameter of $300 \mu \mathrm{m}$, and Kandlikar et al. [17], who employed diameters of $1.06 \mathrm{~mm}$ and $0.62 \mathrm{~mm}$ tubes elucidated that because of the roughness their friction factors were higher than theory. However, Kandlikar et al. [17] specified that the effect of surface roughness (relative roughness of $0.36 \%$ ) was significant only for the smallest diameter test section $(0.62 \mathrm{~mm})$. Shen et al. [9] studied flow and heat transfer for deionized water in rough-walled copper microchannels assembled in a 26-channel array. The rectangular channels were $300 \mu \mathrm{m}$ wide and $800 \mu \mathrm{m}$ deep. They applied three different inlet temperatures; $30^{\circ} \mathrm{C}, 50^{\circ} \mathrm{C}$ and $70^{\circ} \mathrm{C}$ and their Reynolds numbers varied from 162 to 1257 . They found that the effect of surface roughness (relative roughness 4 $6 \%$ ) on laminar flow was significant and that higher inlet temperatures decreased the pressure drop. However, they did not explain the effect of fluid temperature on the friction factor.

In this study, experimental friction factors obtained from flow in different diameters of the tube are compared each other and also compared with theory. The aims are to see if there are any differences of investigated friction factors found in each tube at the same Reynolds numbers. Furthermore, as the test sections used in this research were not equipped with calming sections, pressure drop predictions in the inlet and outlet plenums are analyzed and presented in the forms of graph.

\section{Experimental Facility and Test Sections}

Experiments using the $1.14 \mathrm{~mm}$ diameter tube were performed using the test rig at Brunel University, United Kingdom, see Fig. 1 in Mirmanto et al. [13]. The test rig used in this work consisted of a reservoir made of SS316, micropump (model Micropump GA-T23, PFSB), Coriolis flowmeter (model Micromotion Elite CMF010), preheaters and test sections. Deionized water was used as the working fluid that was set at $30^{\circ} \mathrm{C}$. The water temperature was measured using $\mathrm{K}$ type thermocouple with an uncertainty of $\pm 0.2 \mathrm{~K}$ calibrated against the Platinum Precision Thermometer with an accuracy of $\pm 0.025 \mathrm{~K}$. To obtain pressure drops, two pressure transducers model Honeywell 26PCCD with an uncertainty of $\pm 0.2 \mathrm{kPa}$ were installed in the inlet and outlet and were calibrated against the deadweight tester for high pressures and the water manometer for low pressures. The experiments using $15.5 \mathrm{~mm}$ and $17 \mathrm{~mm}$ tubes were conducted at Mataram University, Indonesia. The test rig used was H408 Fluid Friction Apparatus (see Fig. 1) and the test section were fabricated by TecQuipment Ltd, [10].

The lengths of the test sections were $200 \mathrm{~mm}$ for the $15.5 \mathrm{~mm}$ tube diameter (tapping 30 and 31 ) and $912 \mathrm{~mm}$ for the 17 $\mathrm{mm}$ tube diameter (tapping 7 and 8). The $15.5 \mathrm{~mm}$ tube was roughen using sand grain with an average size of $0.5 \mathrm{~mm}$ giving its relative roughness of 0.032 , see Fig. 2 . The pressure drop was measured using closed manometer with a resolution of $1 \mathrm{~mm}$.

Three test sections employed were (i) a stainless steel tube with an inner diameter of $1.14 \mathrm{~mm}$ (measured using a TSER microscope with an accuracy of $\pm 1 \mu \mathrm{m}$, see Fig. 3), $200 \mathrm{~mm}$ long, equipped with $200 \mathrm{~mm}$ long calming sections placed before and after the test section, (ii) a PVC tube with an inner diameter of $17 \mathrm{~mm}$ and a length of $912 \mathrm{~mm}$ without a calming section, (iii) a PVC rough tube with an effective diameter of $15.5 \mathrm{~mm}$ and a length of $200 \mathrm{~mm}$ without a calming section. 


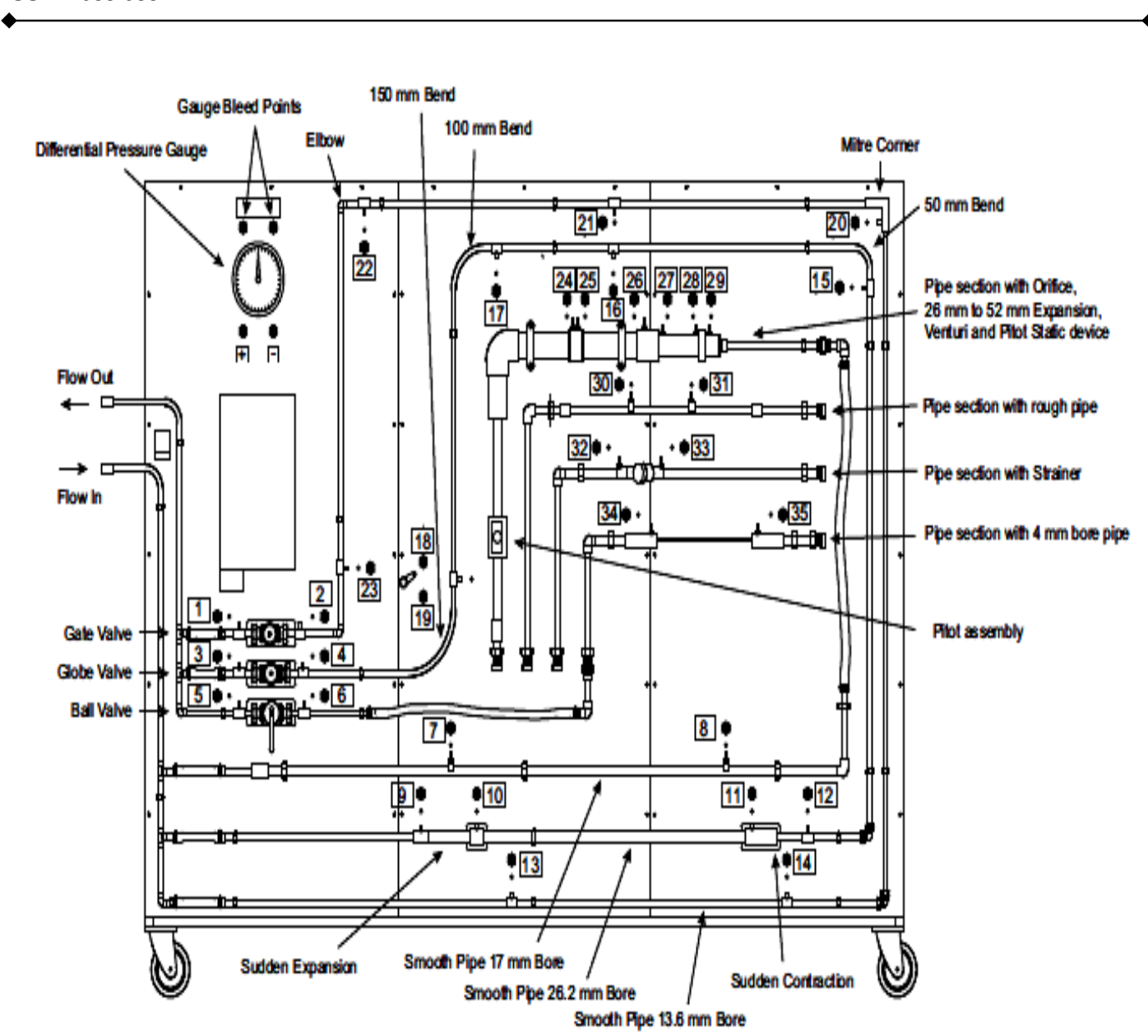

Figure 1. Experimental schematic diagram [10]

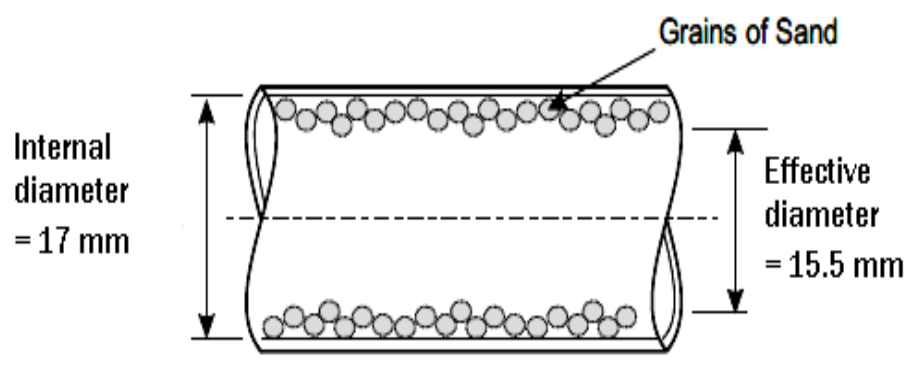

Figure 2. Rough pipe test section 


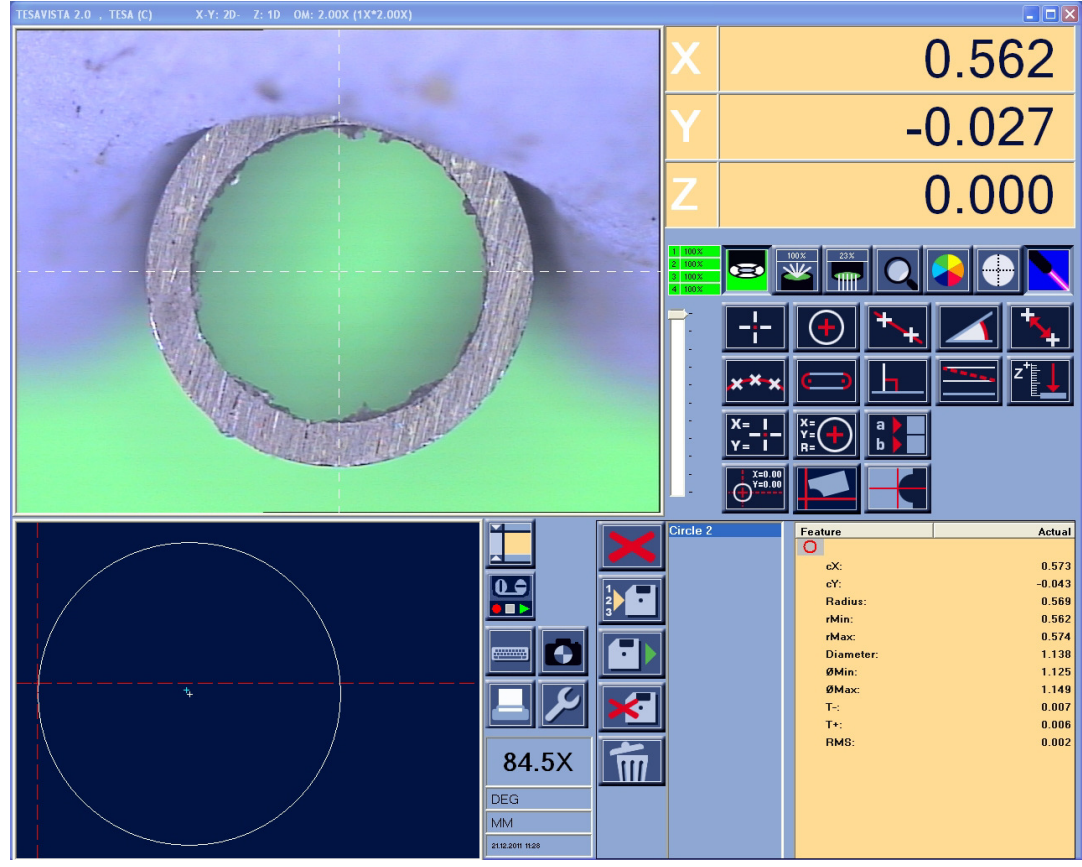

Figure 3. Stainless steel test section measured using a TSER microscope

\section{Data Reduction}

In this study, the inlet and outlet pressures were measured directly, therefore, the pressure drop is obtained by subtracting the outlet pressure from the inlet pressure and called as total pressure drop, taken from [18]:

$$
\Delta p_{t}=p_{i}-p_{o}
$$

where $p_{i}$ is the measured inlet pressure and $p_{o}$ is the measured outlet pressure. The channel pressure drop is then determined using Eq. (3), however, for the test section that is equipped with a calming section, the channel pressure drop is the same as the total pressure drop, Eq. (2), taken from [12]:

$$
\begin{aligned}
& \Delta p_{c h}=\Delta p_{t} \\
& \Delta p_{c h}=\Delta p_{t}-\Delta p_{i}-\Delta p_{o}
\end{aligned}
$$

the inlet and outlet pressure drops are due to the differences between inlet and outlet tube diameters and channel diameter. Meanwhile, in the outlet, there is a pressure recovery due to the deceleration of the fluid. The inlet and outlet pressure drops can be estimated as follows:

$$
\begin{aligned}
& \Delta p_{i}=\Delta p_{l}+\Delta p_{a}=\rho k_{l} V_{c h}^{2} / 2 \\
& +\rho V_{c h}^{2}\left(1-\left(A_{c h} / A_{i}\right)^{2}\right) / 2 \\
& \Delta p_{o}=\Delta p_{l}-\Delta p_{d}=\rho k_{l}\left(V_{c h}-V_{o}\right)^{2} / 2 \\
& -\rho V_{c h}^{2}\left(1-\left(A_{c h} / A_{o}\right)^{2}\right) / 2
\end{aligned}
$$

where $\Delta p$ is the static pressure drop, $\Delta p_{a}$ is the pressure drop due to fluid acceleration and $\Delta p_{d}$ is the pressure recovery due to fluid deceleration. $A_{c h}$ is the channel cross sectional area, $A_{i}$ is the inlet plenum cross sectional area and $A_{0}$ is the outlet plenum cross sectional area. $V_{c h}$ is the average channel fluid velocity and $V_{o}$ is the average outlet plenum fluid velocity. kis the loss coefficient that is equal to 1 for Eq. (5) and dependent on the ratio of channel diameter and inlet plenum diameter for Eq. (4), see Table 1, whilst $\rho$ is the fluid density.

The experimental friction factor, $f$, is calculated using Eq. (6), which is given by (taken from [21]).

$$
f=\frac{2 \Delta p_{c h} D_{c h}}{\rho L V_{c h}^{2}}
$$

where $L$ is the channel length and $D_{c h}$ is the channel diameter. The friction factor theory in this study is the Darcy-Weisbach equation for laminar which is given by, taken from [21]. 


$$
f=\frac{64}{\operatorname{Re}}
$$

and for turbulent flow in the smooth pipe, the friction factor equation used is Blasius equation which is expressed as, taken from [21].

$$
f=0.316 \operatorname{Re}^{-0.25}
$$

whilst for turbulent flow in a rough channel, the friction factor formula selected is Colebrook-White equation or Moody diagram which is written as [18]:

$$
\frac{1}{\sqrt{f}}=1.74-0.869 \ln \left(\begin{array}{l}
\frac{2 k}{D_{c h}}+ \\
\frac{18.7}{\operatorname{Re} \sqrt{f}}
\end{array}\right)
$$

where $k$ is the channel absolute roughness and $R e$ is the Reynolds number.

The goodness of data is analyzed using error analysis proposed by Coleman and Steele [19]. In this study the errors consist of bias/systematic and random errors. Systematic errors can be minimized with a calibration whilst random errors cannot. Following Coleman and Steele [19], the random uncertainty of a measured variable, $X$, is estimated as the standard deviation, $S_{X}$, of a sample of $N$ measurements of the variable, $X$, calculated as follows, taken from [19]:

$$
\begin{aligned}
& S_{x}=\sqrt{\frac{1}{N-1} \sum_{i=1}^{N}\left(X_{i}-\bar{X}\right)^{2}} \\
& \bar{X}=\frac{1}{N} \sum_{i=1}^{N} X_{i}
\end{aligned}
$$

where $\bar{X}$ is the mean value of the sample population. By contrast, the systematic uncertainty of a measured variable, $X$, is calculated as the root sum (RSS) given by Eq. (12), taken from [19].

$$
B_{X}=\sqrt{\sum_{k=1}^{M}\left(B_{X}\right)_{k}^{2}}
$$

Where $\left(B_{x}\right)_{j}$ is the $j^{\text {th }}$ of the elemental systematic uncertainties $\left(B_{x}\right)_{1}, \quad\left(B_{x}\right)_{2}$, $\left(B_{x}\right)_{3}, \ldots \ldots\left(B_{x}\right)_{M}$, estimated from, for example calibration data and instrument specifications given by the manufacturers. The combined error $u_{c}$ is then given by Eq. (13) and the propagated error can be estimated using Eq. (14), taken from [19].

$$
u_{c}=\sqrt{B_{x}^{2}+S_{x}^{2}}
$$

$$
U_{r}=\sqrt{\begin{array}{l}
\left(\frac{\partial r}{\partial X_{1}}\right)^{2} U_{X_{1}}^{2}+\left(\frac{\partial r}{\partial X_{2}}\right)^{2} U_{X_{2}}^{2} \\
+\ldots \ldots \ldots \ldots . .+\left(\frac{\partial r}{\partial X_{j}}\right)^{2} U_{X_{j}}^{2}
\end{array}}
$$

Equation (14) gives the absolute uncertainty, $U_{r}$, in the result.

Table 1. $k$, loss coefficient for the sudden contraction, taken from [10]

\begin{tabular}{cc}
\hline$D_{c h} / D_{i}$ & $k_{t}$ \\
\hline 0 & 0.50 \\
0.2 & 0.45 \\
0.4 & 0.38 \\
0.6 & 0.28 \\
0.8 & 0.14 \\
1.0 & 0 \\
\hline
\end{tabular}

\section{Results and Discussions}

The inlet and outlet pressures have been measured and the total pressure drop obtained from the three test section is presented in Fig. 4. The test section \#1 is the smooth test section with a diameter of 1.14 $\mathrm{mm}$ equipped with calming sections installed before and after the test section, therefore, the total pressure drop is the same as the channel pressure drop and the associated flow is fully developed flow. The test section \#2 is the smooth test section with a diameter of $17 \mathrm{~mm}$ and without a calming section and the test \#3 is the rough test section with an average diameter of $15.5 \mathrm{~mm}$ (the actual diameter is $17 \mathrm{~mm}$ and the effective diameter is $15.5 \mathrm{~mm}$ ) and without a calming section. From Fig. 4, it is clear that decreasing in diameter increases the pressure drop significantly. For example, the decrease in diameter from $17 \mathrm{~mm}$ to $15.5 \mathrm{~mm}$, the pressure drop deviates of about $400 \%$ of the pressure drop obtained in the $17 \mathrm{~mm}$ tube diameter at the same Reynolds number of 20000, whilst from $17 \mathrm{~mm}$ to $1.14 \mathrm{~mm}$ the pressure drop deviates of approximately $166567 \%$ of the pressure drop gained in the $17 \mathrm{~mm}$ tube diameter at the same Reynolds 
number of 3000 . This is becoming a serious problem in the use of small to micro channels.

In Fig. 4, the pressure drops were measured in the test section with diameters of $15.5 \mathrm{~mm}$ and $17 \mathrm{~mm}$ and without a calming section, unless for the $1.14 \mathrm{~mm}$ tube diameter. Therefore, to obtain the channel pressure drop Eq. (3) to (5) should be employed. The cross sectional channel area for the $15.5 \mathrm{~mm}$ tube diameter is equal to $0.000154 \mathrm{~m}^{2}$, whilst for the $17 \mathrm{~mm}$ tube diameter is $0.000227 \mathrm{~m}^{2}$, therefore, flow velocities in the channel can be calculated as, taken from [17]:

$$
V_{c h}=\frac{\dot{m}}{\rho A_{c h}}
$$

where $\dot{m}$ is the mass flow rate. For the 17 $\mathrm{mm}$ tube diameter, Eq. (4) and (5) result in zero pressure drop because the inlet and outlet plenum diameters were the same as the channel diameter, whilst for the $15.5 \mathrm{~mm}$ tube diameter were not. The loss coefficients for the $15.5 \mathrm{~mm}$ tube diameter are approximately 0.14 for Eq. (4) and 1 for Eq. (5). Pressure drops obtained in the $15.5 \mathrm{~mm}$ tube diameter are higher than those in the 17 $\mathrm{mm}$ tube diameter. This was obviously due to the surface roughness or rough channel wall and channel diameter.

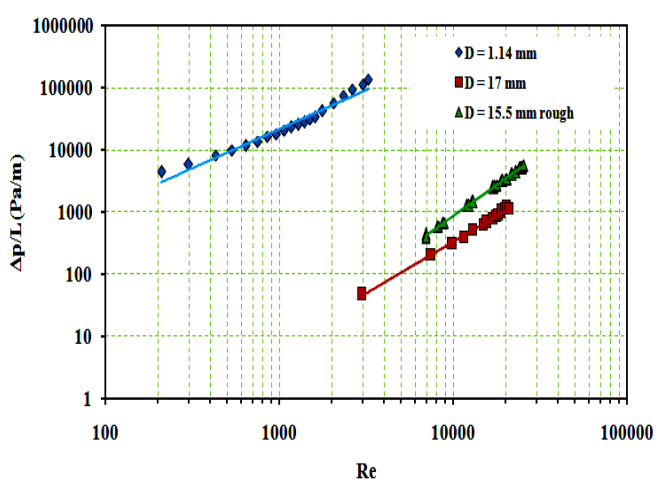

Figure 4. Total pressure drops per meter obtained from flow in the three test sections

As there are many contradictory results in experiments that use small to micro channels, in this occasion, experimental friction factors are presented in Fig. 5 and discussed. The theories used for comparison with the experimental data are Eq. (6) trough Eq. (9). In addition, a correlation proposed by Mirmanto [20] is also used here to see the accuracy of the correlation. The correlation of friction factor in [20] was proposed for flow in rectangular channels with diameters ranging from $0.438 \mathrm{~mm}$ to $0.635 \mathrm{~mm}$ and without a calming section or it is for developing flow. the correlation is expressed as

$$
f=12.55 \operatorname{Re}^{-0.92}
$$

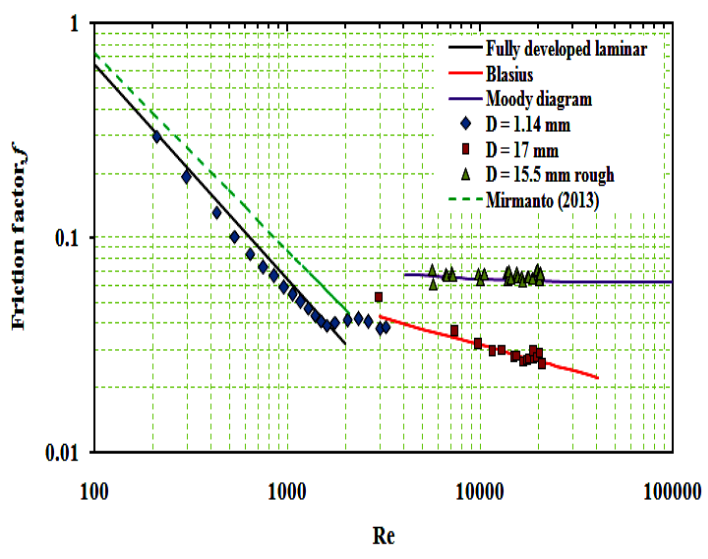

Figure 5. Experimental friction factors

In the Fig. 5, the experimental friction factors are in a good agreement with the theory. The friction factor for the $15.5 \mathrm{~mm}$ tube diameter obeys the Moody diagram at $k / D=0.032$ after all minor losses are subtracted from the total pressure drop. The deviation between total pressure drop and channel pressure drop is approximately $16.4 \%$. For the $17 \mathrm{~mm}$ tube diameter, the friction factor agrees well with Blasius [21] correlation for smooth pipe. However, for the $15.5 \mathrm{~mm}$ and $17 \mathrm{~mm}$ tube diameters, laminar experiments could not be performed due to their lengths. if the lengths were quite long, then in laminar flow, the pressure difference could be read. Additionally, the friction factor obtained in the $15.5 \mathrm{~mm}$ tube diameter is higher than that obtained in the $17 \mathrm{~mm}$. This is not due to the tube diameter but the roughness. Meanwhile, the correlation proposed by Mirmanto [20] over predicts the data, because the correlation was created for developing flow condition and rectangular channels. Hence, it evidences that the friction factor is not affected by the diameter but by several factors such as entrance condition, minor losses and developing flow condition.

To ensure that the experimental data agree with the theory, an excel analysis and error analysis have been performed. Examples of excel analysis and error analysis are described here. Consider the experimental data obtained in the $17 \mathrm{~mm}$ tube diameter, using excel analysis (ANOVA regression), the significance $F$ is small to be 
compared with $F$ values. It means that there is no deviation between the experimental results and the theory, see Table 2 . Additionally, an error analysis following Coleman and Steele [19] is presented in Fig. 6 for the data obtained for the $17 \mathrm{~mm}$ tube diameter. The first point with big error bars indicating the furthers point, still covers the Blasius [21] correlation, hence, the data are in a good agreement with the theory. The error bars for the experimental friction factor shown in Fig. 6 are given by, using equation proposed by [19]:

$$
\frac{U_{f}}{f}=\left[\begin{array}{l}
\left(\frac{U_{\Delta p_{c h}}}{\Delta p_{c h}}\right)^{2}+\left(\frac{U_{D_{c h}}}{D_{c h}}\right)^{2}+ \\
\left(\frac{U_{L}}{L}\right)^{2}+\left(\frac{2 U_{V_{c h}}}{V_{c h}}\right)^{2}
\end{array}\right]^{1 / 2}
$$

The uncertainty of the pressure drop, diameter, tube length and fluid velocity are known from the experiments, hence, the relative error of friction factors can be found and shown in Fig. 6.

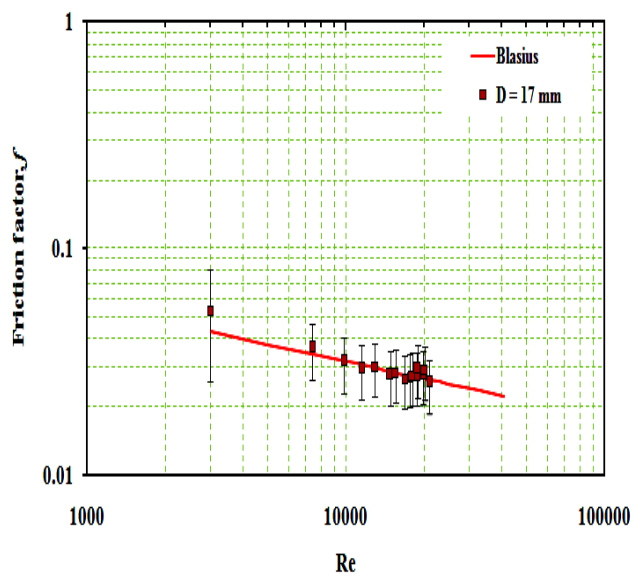

Figure 6. Error analysis for data obtained for the $17 \mathrm{~mm}$ tube diameter

Table 2. Excel analysis using ANOVA regression

SUMMARY OUTPUT

\begin{tabular}{lr}
\hline \multicolumn{2}{c}{ Regression Statistics } \\
Multiple R & 0.964487317 \\
R Square & 0.930235785 \\
A djusted R & \\
Square & 0.924869307 \\
Standard Error & 0.000293979 \\
Observations & 15 \\
\hline
\end{tabular}

\begin{tabular}{|c|c|c|c|c|c|}
\hline & $d f$ & SS & $M S$ & $F$ & Significance $F$ \\
\hline Regression & 1 & $1.49809 \mathrm{E}-05$ & $1.498 \mathrm{E}-05$ & 173.34195 & $6.82013 \mathrm{E}-09$ \\
\hline Residual & 13 & $1.12351 \mathrm{E}-06$ & $8.642 \mathrm{E}-08$ & & \\
\hline Total & 14 & $1.61044 \mathrm{E}-05$ & & & \\
\hline
\end{tabular}

\begin{tabular}{lllllllll}
\hline & \multicolumn{3}{c}{ Standard } & & & & \multicolumn{2}{l}{ Lower } \\
& Coefficients & Error & tStat & P-value & Lower 95\% & Upper 95\% & 95.0\% & Upper 95.0\% \\
\hline Intercept & 0.002699278 & 0.000361599 & 7.4648378 & $4.732 \mathrm{E}-06$ & 0.001918091 & 0.003480465 & 0.001918091 & 0.003480465 \\
X Variable 1 & 0.152781938 & 0.011604333 & 13.165939 & $6.82 \mathrm{E}-09$ & 0.127712302 & 0.177851575 & 0.127712302 & 0.177851575 \\
\hline
\end{tabular}

\section{Conclusion}

Experiments to see the difference of friction factors obtained for flow in several different diameter tubes have been performed. For the 1.14 tube diameter, the experiments were conducted at the Brunel University, whilst for other test sections were performed at the Mataram University. The results show that, for both experiments conducted in different locations, the experimental friction factors are not influenced by the size of the tubes but by the condition of the entrance and surface roughness, and they obey the theory very well. However, as the size of the tubes reduces, the pressure drop increases drastically.

\section{Acknowledgement}

The first author would like to acknowledge the Indonesia Higher Education 
for the funding, and the Brunel University and Mataram University for the facilities.

\begin{tabular}{|c|c|c|c|}
\hline \multicolumn{4}{|c|}{ Nomenclature } \\
\hline$A$ & Cross sectional area $\left[\mathrm{m}^{2}\right]$ & $p$ & Measured pressure $[\mathrm{Pa}]$ \\
\hline$B_{x}$ & Systematic uncertainty & $R$ & Regression \\
\hline$D$ & Diameter & $\operatorname{Re}$ & Reynolds number \\
\hline$d f$ & Degree of freedom & $S_{x}$ & Standard deviation \\
\hline$f$ & Friction factor & $u_{c}$ & Combined error \\
\hline$j$ & Number of element systematic uncertainty & $U_{r}$ & Propagated error of $r$ function \\
\hline$k$ & Absolute roughness $[\mathrm{m}]$ & $V$ & Channel average velocity $[\mathrm{m} / \mathrm{s}]$ \\
\hline$k_{l}$ & Losses coefficient & $X$ & Measured variable \\
\hline$L$ & Tube length $[\mathrm{m}]$ & $\bar{X}$ & Average of measured variable \\
\hline$M$ & $\begin{array}{l}\text { Maximum number of element systematic } \\
\text { uncertainty }\end{array}$ & & \\
\hline$\dot{m}$ & Mass flow rate $[\mathrm{kg} / \mathrm{s}]$ & & \\
\hline$N$ & Number of measurements & \multicolumn{2}{|c|}{ Subscript } \\
\hline & & ch & Channel \\
\hline & & $i$ & Inlet \\
\hline \multicolumn{2}{|c|}{ Greek symbol } & $o$ & Outlet \\
\hline$\Delta p$ & Pressure drop $[\mathrm{Pa}]$ & $t$ & Total \\
\hline$\rho$ & Fluid density $\left[\mathrm{kg} / \mathrm{m}^{3}\right]$ & & \\
\hline
\end{tabular}

\section{References}

[1] Brauner, N. \& Moalem-Maron, D., 1992, "Identification of the range of small diameter conduits regarding two-phase flow pattern transitions", International Communications Heat Mass Transfer, Vol. 19, 29 - 39.

[2] Kew, P.A. \& Cornwell, K., 1997, "Correlations for the prediction of boiling heat transfer in small diameter channels", Applied Thermal Engineering, Vol. 17(8-10), $705-715$.

[3] Peng, X.F.\&Wang, B.X., 1998, "Forced convection and boiling characteristics in microchannel", Proc. of $11^{\text {th }}$ IHTC, 1, Korea, 371 390.

[4] Mahendale, S.S., Jacobi, A.M. \& Shah, R.K., 2000, "Fluid flow and heat transfer at micro and messo scale with application to heat exchanger design", Applied Mechanics Reviews, Vol. 53(7), $175-193$.

[5] Kandlikar S.G., 2002, "Two-phase flow patterns, pressure drop, and hear transfer during boiling in minichannel flow passages of compact evaporators", Heat Transfer
Engineering, Vol. 23(1), 5-23.

[6] Urbanek, W., Zemel, J.N. \& Bau, H.H., 1993, "An investigation of temperature dependence of Poiseuille numbers in microchannel flow", J. Micromech. Microeng., Vol. 3, $206-208$.

Papautsky, I., Brazzle, J., Ameel, T., \& Frazier, A., B., 1999, "Laminar fluid behavior in micro channel using micro polar fluid theory", Sensors and Actuator, Vol. 73, 101 - 108.

[7] Papautsky, I., Brazzle, J., Ameel, T. \& Frazier, A., B., 1999, "Laminar fluid behaviour in micro channel using micro polar fluid theory", Sensors and Actuator, Vol. 73, 101 - 108.

[8] Pfund, D., Rector, D. \& Shekarriz, A., 2000, "Pressure drop measurements in a microchannel", Fluid Mechanic and Transport Phenomena, Vol. 46(8), $1496-1507$.

[9] Shen, S., Xu, J.L., Zhou, J.J. \& Chen, Y., 2006, "Flow and heat transfer in microchannels with rough wall surface", Energy Conversion and Management, Vol. 47, 1311-1325.

[10] Anonymous, 2013, "Fluid friction test 
bed manual H408", TecQuipment Ltd, Jakarta.

[11] Silverio, V. \& Moreira, A.L.N., 2008, "Pressure drop and heat convection in single-phase fully-developed, laminar flow in microchannels of diverse cross section", $5^{\text {th }}$ European Thermal Science Conference, the Nederland.

[12] Akbari, M., Sinton, D. \& Bahrami, M., 2009, "Pressure drop in rectangular microchannels as compared with theory based on arbitrary cross section", J. Fluid Engineering, Vol. $131,1-8$.

[13] Mirmanto, Kenning, D.B.R., Lewis, J.S. \& Karayiannis, T.G., 2012, "Pressure drop and heat transfer characteristics for single-phase developing flow of water in rectangular microchannels, Journal of Physics: Conference Series doi:10.1088/17426596/395/1/012085

[14] Jiang, J., Hao, Y. \& Shi, M., 2008, "Fluid flow and heat transfer characteristics in rectangular microchannel", Heat Transfer-Asian Research, Vol. 37,197-207.

[15] Qu, W., Mala, G.M. \& Li, D., 2000, "Pressure-driven water flows in trapezoidal silicon microchannels", Int. J. Heat Mass Transfer, Vol. 43, 353 364.
[16] Jiang, P.X., Fan, M.H., Si, G.S. \& Ren, Z.P., 2001, "Thermal-hydraulic performance of small scale microchannel and porous-media heatexchangers", Int. J. Heat and Mass Transfer, Vol. 44, 1039 - 1051.

[17] Kandlikar, S.G., Joshi, S. \& Tian, S., 2003, "Effect of surface roughness on heat transfer and fluid flow characteristics at low Reynolds numbers in small diameter tubes", Heat Transfer Engineering, Vol.24 (3), 4-16.

[18] Olson, R.M., 1993, "Dasar-dasar mekanika fluida teknik", Edisi 2, Gramedia Pustaka Utama, Jakarta.

[19] Coleman, H.W. \& Steele, W.G., 2009, "Experimentation, Validation, and Uncertainty Analysis for Engineers", $3^{\text {rd }}$ edition, John Wiley and Son, Inc., Hoboken, New Jersey, USA.

[20] Mirmanto, 2013, "Single-phas flow and flow boiling of water in rectangular microchannels", Thesis, Brunel University, Uxbridge, West London, UK.

[21] Hager W.H., 2003, "Blasius: A life in research and education", Experiments in Fluids, Vol. 34, 566-571 doi 10.1007/s00348-002-0582-9. 